\title{
"DEVELOPMENT OF PROFESSIONAL COMPETENCE OF TEMURBEK SCHOOL STUDENTS IN THE PROCESS OF TEACHING ENGLISH"
}

\author{
${ }^{1}$ Alimardonov Zohid Shukurullayevich, ${ }^{2}$ Sapaeva Barno Shanazarovna \\ ${ }^{1}$ Doctor of Philosophy (PhD) of Pedagogical Sciences, Associate Professor, Deputy Head of the Department of Psychology and \\ Pedagogy of the Military-Technical Institute of the National Guard, Uzbekistan. \\ ${ }^{2}$ Teacher, UrgenchTemurbek School, Uzbekistan.
}

\begin{abstract}
:
The article considers the problems of the effectiveness of the formation of professional competence in the study of English by students of the "Temurbek School". To achieve this goal, professionally oriented and competency-based approaches have been used, which involve redesigning the content of learning sessions and tasks to stimulate students' interest. If more attention is paid to combining intensive and extensive types of reading texts, and on this basis to the level of readiness to build an individual route for learning a foreign language, then the effectiveness of the formation of professional competencies is expected to increase.
\end{abstract}

Keywords:

communicative competence, discursive competence of speech, formation of professional competencies, education, students, English.

Article Received: 18 October 2020, Revised: 3 November 2020, Accepted: 24 December 2020

\section{INTRODUCTION}

In the modern context of increasing globalization, the need to train highly qualified natural specialists who know English has become urgent. It is important for a modern specialist not only to communicate with foreign partners, but also to be able to use knowledge of English in professional activities. Knowledge of language promotes effective communication, is a universal tool for successful professional activity and selfawareness. In connection with the above, the requirements for the level of language training and professional competence of graduates of the "Temurbek School" are growing.

The priority in teaching English is to form professional competencies aimed at the practical use of English as a means of pursuing professional interests.

Analysis of pedagogical experience and real practice shows that the complexity of the formation of professional competencies in the study of English among students of the
"Temurbek School" is that students, taking into account their internal consistency, develop a set of professional competencies. should form. In the conducted pedagogical research, we used different methods: the level of language proficiency in the learning process, reading, pronunciation, translation, knowledge of vocabulary by students. The conversation focuses on developing an individual route for language learning, which should determine students ' motivation and interest in meaningful texts. In this regard, the following tasks are clarified: focus on the formation of speech and discursive competencies; formation of English vocabulary on topics; create individual routes for language acquisition to stimulate foreign language learning motivation.

Discursive competence is the ability to receive different types of speech, which allows you to create behavioral strategies and background contexts in the process of professional communication. The formation of lexical 
competence allows to form a meaningful vocabulary, to fill it with different terms in the context of professional activity. Based on the experience of the training sessions and the students in a passive knowledge of the language, in our opinion, taking into account the priority of training and extracurricular activities thematic texts to combine intensive and extensive reading promotion need The text should engage a variety of vocabularies and expand students 'vocabulary accordingly. The interaction of both the text and the verbal situation allows the lexical area to be expanded, the use of words to be easier to implement, and the thematic text to combine lexical and semantic types.

\section{MATERIALS AND METHODS}

Linguistic competence is understood as the acquisition of knowledge of language material (phonetics, vocabulary, grammar) and skills in various types of speech activity (listening, speaking, reading and writing).

Sociolinguistic competence allows the speaker to choose the appropriate language form, style of expression, based on a specific speech situation, communicative goal and desire. Sociolinguistic competence includes socio-cultural competence, the ability to know the national characteristics of authentic speech: customs, values, rituals and other national and cultural characteristics of the country in which they live, and compare them with the country where the language is being studied. Holds the building.

Pragmatic competence means the ability to get out of difficult situations by repeating, apologizing, etc., when misunderstandings arise in a communicative situation in the foreign language being studied. In this standard, discursive competence is included in pragmatic competence. This competence includes the ability to express ideas orally or in writing using appropriate linguistic means. Discursive competence refers to the ability to understand and interpret linguistic cues to ensure consistency in speech or writing.

Phonetic competence Work on the correct pronunciation of words, phrases and speeches.
Use of rhythm and intonation (pronoun, interrogative word, participle, imperative mood); break the sentence into meaningful parts.

Grammatical competence. Adequately correct application of the grammatical material learned at previous levels in a public and professional context (verb tenses, modal words, comparative quality levels and forms, defining words, prepositions, etc.).

Behavioral competence is competence that characterizes a person's individuality in the performance of their professional duties. This includes interpersonal relationships, management style, analytical skills, and goal orientation. They are called "soft requirements" or "soft competences".

Technical (professional) competence is a competence that is directly related to the results of work, standards of professional activity. These are called "strict requirements" or "strict competences".

General competence is competence that characterizes all people in a particular profession. For example, people involved in management. However, it does not matter in which organization a person works or in what position.

Specific competence is the competence required to effectively perform specific professional responsibilities.

Initial competence is the basic competence that an employee needs to fulfill the assigned professional tasks.

Execution competence is the competence that determines the quality of the result achieved.

Differential competence is competence that helps differentiate effective performers to one degree or another. This type of competence exists in the form of models that are influenced by how a professional should behave in a specific task. This can be done with the consent of the manager and the executive performing professional duties.

Competence covers input, output and process systems.

Competence is the actual ability to perform a task that belongs to that group. Includes knowledge, skills, attitudes. Such competencies can be innate 
or acquired during education, training and professional experience.

Competence is the ability to effectively solve a professional problem. The main task is not to evaluate the initial result, but to evaluate the most effective result. In competence, a process is the ability to apply acquired knowledge and skills to achieve an expected result or goal.

In addition, the stages of professional development are the national qualifications of students:

1) "initial stage" - determination of the motivational component of the formation;

2) "flexible stage" - the motivational component of development - professional competence;

3) "cognitive stage" - the acquisition of accumulated knowledge, ie. the cognitive component of the formation of trends;

4) "reflexive stage" - a component of the competence of educational activity and further development of cognition, mitigating the need for active self-education;

5) "stage of activity" - the form of activity, professional applications, creative attitude of students to the study of science.

- indicative component (determination of requirements for the formation of the facility's capabilities);

- the operational component (knowledge that forms the ability to apply);

- an experience. The authors of the analysis of modern works can highlight such common features of the concept as the right to acquire knowledge, skills and abilities. In the context of informatization, higher education can be included in the profession Component of the formation of competencies, demonstration collection, storage and processing of students. - epistemological (acquisition and accumulation of new knowledge); - activity (skills);

- personal (professional) but personal qualities);

- reflective (the ability to self-esteem);

- motivational value (motives and value relationships);

- communicative (possessive) people, mental communication skills (teamwork);
- Information. All these components are connected with each other by us together and in the mind of one reader as a whole, their interconnection and communication.

\section{RESULT AND DISCUSSION}

The process of formation of professional competencies in the study of English by students serves as an integral feature of the achievement of the main result - the training of a highly qualified specialist. The introduction of an integral competency that ensures communication in English in the field of professional speech and the readiness to interact in a professional English-speaking environment will increase the effectiveness of language teaching for students. Therefore, the introduction of professional competencies that reflect the integral feature of the formation of competencies in the classroom for learning English is an urgent requirement. It should be noted here that there is a need for skills and competencies in listening and speaking comprehension for natural profile students to effectively communicate in English. In the field of professional activity, attention should be paid to the formation of speech competencies in order to successfully master speaking English. It is advisable to form these skills in creating a professionally oriented English-speaking communication environment, which involves combining the study of English as a means of acquiring one's specialization and a means of expanding professional communication. This requires changes in the content of education and the structure of training.

When organizing training sessions, it is necessary to pay attention to the following: the types of speech practice should be related to the specific features of the acquired specialization; verbal interaction should be consistent with the set goals, for which it is necessary to organize not only group communication, but also the purposeful implementation of independent work by students; focus on the content of the speech, not on the grammatical rules. 
The formation of professional competencies requires the development of listening and speaking skills in English, taking into account the professional training and language scope in future professional activities. The analysis of the process of teaching English, the organization of teaching texts, assignments, the content of exercises, as well as the forms and methods of teaching activities led us to implement a multi-stage approach to teaching. This approach involves emphasizing the individual direction of language acquisition in order to create a positive motivation for language learning. This approach allows for a step-by-step coordination of the level of knowledge in the study group, which then allows for the use of different forms of lessons, group communication, as well as practical demonstrations of the role of English language skills in trainings, presentations, articles and scientific conferences. explains.

The next logical step in improving English teaching is to organize independent work that is relevant to the learning process. Such pedagogical tactics allow students to increase their subjectivity and develop professional training, to understand the importance of mastering the English language as a factor in improving professional training. The introduction of effective teaching methods implies that the subject of the texts should reflect the interests of the reader and include professional information, i.e. it should have an individual character that implies the variability of the text and assignments ; the content of the lessons should reflect an acquaintance with the biodiversity and resources of the country and individuals, i.e. reflect professional orientation; the use of phraseological twists, proverbs and sayings in accordance with the professional direction should serve to achieve automation in the mastery of speech structures; the creation of dialogue structures increases communicative competence; activating the humanities knowledge that is manifested in revealing the interrelationships between science, fiction, and the activities of celebrities, helps to expand speech.

When taking an English course, students must have the following skills

Listening comprehension: audio, video, media products, information on the Internet, television and radio broadcasting, understanding films and defining the main idea of the profession related to various fields, words related to work or daily life, etc. speech, used in its meaning, with its combinations and phrases, to be able to participate in discussions based on audio text, to understand conversations in various situations during a visit to the country where the language is being studied, the main idea of information about environmental events is to be able to understand, analyze and react;

Conversational speech: be able to analyze and express the attitude of the countries in which the language is being studied, on topics such as government, management and the education system, career guidance, economics, communication system, the Internet, media education, literature and art, in order to be able to transform expressions into meaningful words and phrases, use quotes and assimilation in the speech process, confidently communicate on familiar topics related to their field, exchange ideas, be able to check and respond to information, analyze and respond to problem situations;

Reading: the ability to read unfamiliar text in various fields, distinguish necessary information from unfamiliar text, understand, analyze and respond to information, text and news describing an event, 170-190 per minute, in order to be able to read at the speed of words, be able to perform complex exercises based on the text read.

Writing: Ability to compose a text of an average of 250-300 words on a topic of interest, analyze and express attitude to the text in different areas, express a small opinion on an unfamiliar topic with the help of reason, write a biography in order to be able to apply, fill out questionnaires, use methods and forms of writing letters (informal), email, SMS, notes, messages, reports, articles and diaries, to check written work, no It is important 
to be able to analyze and correct mistakes, perform complex exercises based on text and data. It is impossible for students to work independently in the conditions of modern reality without the use of information and communication technologies (ICT). The main advantages of the use of ICT are not only an increase in students' interest in the subject, the creation of realistic conditions, but also an important tool for the development of competencies; optimizing the construction of individual routes for learning a foreign language. ICT allows you to reveal the creative potential and abilities of students, to show a creative approach to solving tasks, to diversify activities (project technologies, presentations, webinars, the practice of finding the necessary information, etc.), which which in turn leads to an expansion of the integral. Speech, discursive, communicative - opportunities for the formation of professional competencies in solidarity and interdependence.Theuseof ICT in English language learning increasesstudents'subjectivity and expands opportunities for self-development and self-expression. The conditions for the formation ofprofessionalcompetencies are to level the level of training in the study group by organizing group communication in English, to create individual-oriented directions for language learning. It is important to expand vocabulary on professional topics by combining intensive and extensive reading of texts in classroom activities. Extensive reading implies an emphasis on the correct interpretation of texts. We believe that the combination of intensive and extensive reading is important.Methodologically important is the importance of thematic texts as a basis for expanding vocabulary and lexical-semantic typology.In real practice, the use of this approach, if necessary, can help to strengthen and enhance the learning process.

\section{CONCLUSION}

Thus, the process of developing professional competencies is not limited to the scope of the educational process. The subjectivity of the studentmotivation to learn English language and professional defy the students on a regular basis to launch the mechanism of formation.

\section{LIST OF REFERENCES}

[1] Azarova V.M. Patriotic education of servicemen of the Armed Forces of the Russian Federation in 1992-2000. Diss. ... doc. historical sciences. - Moscow, 2004. $217 \mathrm{p}$.

[2] Alimardonov Z.Sh. Effective opportunities of contextual technology in training future military specialists // Problems of modern education. Russia. - 2017. -№ 3. - S. 2831.

[3] Alimardonov Z.Sh. The problem of professional and communicative competence of future officers in the works of foreign and Russian scientists "/" Journal of Historical Sciences ". USA. 2018.-№ 2. - S. 55-58.

[4] V. I. Baydenko Competencies in vocational education(to the development of a competence-based approach) / V.I.Baidenko // Higher education in Russia. - 2004. - No. 11. - S. 3-13.

[5] Batyushkin S.A. Military education problematic issues and ways to solve them / S.A. Batyushkin, A.A. Korabelnikov // Bulletin of the Academy of Military Sciences. - 2013. - No. 2 (43) - S. 105-110.

[6] Mamatulov Kh.A. Improving information and technical support for the development of professional competence in foreign languages in teachers // ped.fan. philosophy on. doct. (PhD) Diss. T .: 2017. - 174. P

[7] D.V. Meshcheryakov Model of the formation of professional competence of future officers in the educational process of a military university / A.V. Beloshitsky, D.V. Meshcheryakov // Bulletin of the Tambov State University. Series: Humanities. - 2012.

[8] No. 11 (114). - S. 122-129.Mirabile R.J. Everything you wanted to know about competency modeling / R.J. Mirabile // 
Training and development. - 1997. - P. 73-77

[9] U.S. Air Force Academy. (2016). What it's like to be a cadet?Retrieved fromhttp://www.academyadmissions.com/ what-to-expect/at-the-academy/as-a-cadet/ United States Coast Guard. (2016). Team coordination training student guide: 8/98.Retrieved

fromhttps://www.uscg.mil/auxiliary/trainin $\mathrm{g} / \mathrm{tct} /$. 